\title{
IMMUNITY OF GUINEA-PIGS TO DIPHTHERIA TOXIN AND ITS EFEECT UPON THE OFFSPRING.
}

\section{Part 3.}

(Continued from Vol. XI, p. 442.)

By H. J. SÜDMERSEN, Pн.D. AND A. T. GLENNY, B.Sc.

\section{G. Evidence of lowered resistance in the offspring of normal does and injected bucks.}

THE results of our tests upon the young of normal does and immune bucks agree with those of other workers in showing that no immunity is transmitted through the male parent. At first only a few experiments were performed to act as a confirmation of work already done by those previously engaged upon the subject, but in these few experiments not only was no immunity shown, but there appeared slight evidence that the young of normal mothers and injected fathers possessed increased susceptibility to diphtheria toxin. Such evidence was also seen in the case of the young of normal fathers and injected mothers as already recorded in Part 2. It appeared, therefore, of importance to endeavour to increase the number of observations until the lowering of resistance of offspring from an injected male parent could be either definitely established or disproved. It was found that the number of experiments necessary to establish the point firmly was prohibitive, but a sufficient number of observations were made to strengthen considerably the probability of the correctness of our conclusions. Evidence submitted by other workers may be forthcoming that taken together with our own results may form conclusive evidence.

When a number of normal guinea-pigs of the same weight and age are injected with the same volume of the same toxin and kept under identical conditions the majority of animals will die at the same time, but some 


\section{H. J. SüDmersen AND A. T. Glenny}

marked discrepancies will occur. The dose of toxin used as the Normal Lethal Dose in these experiments was that which usually caused the death of a guinea-pig on the fifth day after the injection. Many normal guinea-pigs injected with this dose would die earlier (mostly on the 4th day) while in others, death would be delayed until the 6th to 10th day, while an occasional pig might even survive.

As has already been pointed out, the quantity of a given toxin that will kill a guinea-pig within a certain time varies with the time of year, and so in all cases normal pigs were injected as controls to the experimental animals and the dose was varied from time to time as was necessary to make allowance for the slight seasonal variation in order to keep the average lethal time as near to five days as possible.

The difference noted in the young of injected bucks was of the same order as the difference occurring among normal pigs and very few individual cases were sufficiently marked to be of any significance, but it was repeatedly seen that the difference between the groups of pigs was always in the same direction. An analysis of results showed that when pigs bred from injected bucks and normal does were injected at the same time as normal control pigs of the same weight with the same dose of toxin, at least half of the young from injected bucks died earlier than the young from normal parents. The results are summarised according to whether the experimental young died when the controls survived, or whether they died earlier, at the same time (within 12 hours), or later, or whether they lived when the controls were killed by the same dose. If the pigs under consideration were of normal susceptibility it would be expected that the numbers dying earlier or later than the mean time of death of the controls would balance. To show how far this would be true among relatively small groups of pigs the results of all pairs of normal pigs treated upon the same day with the same dose of toxin have been analysed in Table XL. An arbitrary distinction between the two pigs in each instance was made by comparing the result of the pig marked with the earlier letter with that of the other which thus takes the place of 'control.' This distinction can have no bearing upon the results because in all cases the normal pigs to be injected are collected together and then taken up indiscriminately and marked with a distinctive letter; later, at the time of injection the marked pigs are taken one at a time without any regard to the letters by which they are known and not until each pig is injected is its distinctive letter noted. Thus it will be seen that the division made is quite arbitrary and the summary of results should give a close Journ. of Hyg. xII 
approximation of what would be expected between our experimental young and the normal controls if the former were of normal susceptibility to diphtheria toxin. Table XL gives two groups of pigs-those injected with Toxin jar $98 \mathrm{~A}$ with which all the tests recorded in this section were performed, and those injected during the same period with any other toxin that was tested on pairs of normal pigs. In both groups the figures are closely balanced-in the first group 13 appear more susceptible and 12 less so, and in the other group the corresponding numbers are 24 and 26.

\section{TABLE XL.}

Comparing the results of the injection of the same dose of toxin at the same time into pairs of normal pigs divided according to an arbitrary distinction between the members of each pair.

$\begin{array}{lccccc}\text { Toxin tested } & \begin{array}{c}\text { Dying when } \\ \text { other lived }\end{array} & \begin{array}{c}\text { Dying } \\ \text { earlier }\end{array} & \begin{array}{c}\text { Dying at the } \\ \text { same time }\end{array} & \begin{array}{c}\text { Dying } \\ \text { later }\end{array} & \begin{array}{c}\text { Livingwhen } \\ \text { other died }\end{array} \\ \text { Jar 98 A } & 1 & 12 & 13 & 11 & 1 \\ \text { Other toxins } & 2 & 22 & 21 & 23 & 3 \\ \text { Total } & 3 & 34 & 34 & 34 & 4\end{array}$

These figures are interesting in showing the extent of variation to be expected when testing the Minimal Lethal Dose of diphtheria toxin upon guinea-pigs, but further analysis of or comments upon these figures is beyond the range of the present paper. We might, however, note in passing that, from this table, 7 survivals may be expected out of a total of 218 pigs injected with a dose that usually kills on the fifth day.

The total number of experimental young (i.e. young got from normal does by injected bucks) tested was 107 and of these 8 died where control survived as opposed to 1 living whose control died and 48 died earlier as compared with 20 dying later. The total number of results given in Table XL is practically the same and these are contrasted in Table XLI.

\section{TABLE XLI.}

Contrasting the results of injection of toxin into experimental young (i.e. young got from normal does by injected bucks) compared with normals and results obtained on comparing pairs of normal pigs.

\begin{tabular}{|c|c|c|c|c|c|c|}
\hline & \multicolumn{6}{|c|}{ Number of pigs under observation } \\
\hline & $\begin{array}{l}\text { Dying when } \\
\text { control lived }\end{array}$ & $\begin{array}{l}\text { Dying } \\
\text { earlier }\end{array}$ & $\begin{array}{l}\text { Dying at } \\
\text { same time }\end{array}$ & $\begin{array}{l}\text { Dying } \\
\text { later }\end{array}$ & $\begin{array}{l}\text { Living when } \\
\text { other died }\end{array}$ & Total \\
\hline Normal pigs & $\mathbf{3}$ & 34 & 34 & 34 & 4 & 109 \\
\hline Experimental young & 8 & 48 & $\mathbf{3 0}$ & 20 & 1 & 107 \\
\hline
\end{tabular}


A marked contrast will be seen in the results of the experimental young as compared with the normal, shown by a shifting of the figures to the left indicating increased susceptibility.

We have now to consider to what extent these figures are significant. It is possible that the conditions under which the experimental young were bred differed sufficiently from the normal to account for these differences. Normal pigs were bred in large open runs from which does were removed to single cages when well advanced in pregnancy, while the majority of experimental young were bred in single cages containing the injected buck and a normal doe. A total' of 41 experimental young were bred under conditions identical with those for the normal controls and of these 21 appeared more as compared with 10 less susceptible than the controls. These figures are given" in Table XLII contrasted with a batch of normal pairs of similar numbers.

\section{TABLE XLII.}

Contrasting the results of injection of toxin into experimental young compared with normals and the results obtained in comparing pairs of normal pigs, taking into account only such experimental pigs as were bred under conditions identical with those of the normal.

\begin{tabular}{lcccccc} 
& \multicolumn{6}{c}{ Number of pigs under observation } \\
Normal pigs & $\begin{array}{l}\text { Dying when } \\
\text { control lived }\end{array}$ & $\begin{array}{c}\text { Dying } \\
\text { earier }\end{array}$ & $\begin{array}{c}\text { Dying at } \\
\text { same timo }\end{array}$ & $\begin{array}{c}\text { Dying } \\
\text { later }\end{array}$ & $\begin{array}{c}\text { Living when } \\
\text { other died }\end{array}$ & Total \\
Experimental young & 1 & 12 & 13 & 11 & 1 & 38 \\
& 2 & 19 & 10 & 10 & 0 & 41
\end{tabular}

Here again the shifting of the figures to the left is strong indication of increased susceptibility among the experimental young.

An analysis of the results among the experimental young bred under conditions differing slightly from the normal showed that young of bucks but little affected by the injection showed no evidence of increased susceptibility while marked results were obtained with the young of bucks decidedly affected by the injection. ' As in the previous sections of this paper the effect of the injection is judged by the local reaction, the change in weight and by the excess of antitoxin in the toxin-antitoxin mixture. Table XLIII shows that in whatever way the effect of the injection upon the buck is measured there is a marked shifting of figures to the left when the buck is severely affected, while in spite of slight differences in condition of breeding the young of bucks but little affected by the injection give results closely approximating to normal. 


\section{TABLE XLIII.}

Dividing the result of the injection of toxin into experimental young according to the severity of the effect of the injection upon the bucks.

Local reaction:

$\overbrace{\begin{array}{c}\text { Dying when } \\ \text { control lived }\end{array}}^{\begin{array}{c}\text { Dying } \\ \text { earlier }\end{array}} \overbrace{\begin{array}{c}\text { Dying at } \\ \text { same time }\end{array}}^{\text {Number of pigs under observation }} \underbrace{\begin{array}{c}\text { Living when } \\ \text { other died }\end{array}}_{\begin{array}{c}\text { Dying } \\ \text { Later }\end{array}}$

No swelling

Large ,"

Change in weight:

Gain

Loss

Excess of antitoxin:

Over $20 \%$

Under $20 \%$

0

2

0

4

0 5

6

17

8

22

\section{5}

14

's

9

18

$\begin{array}{ll}4 & 0 \\ 7 & 0\end{array}$

0

0

110

In addition to the above figures for single toxin-antitoxin mixtures results were recorded for the young of bucks receiving toxin-antitoxin mixtures containing excess of horse serum, horse serum alone, toxin alone and toxin into bucks already rendered passively immune by maternal transmission. These are given in Table XLIV.

\section{TABLE XLIV.}

Further results divided according to the nature of the injection received by the buck.

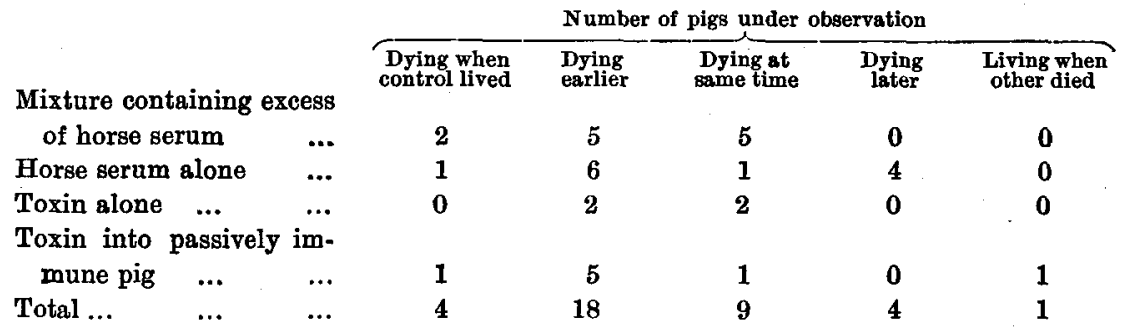

The results thus far recorded show that when conditions of breeding among the experimental pigs were identical with those of normal pigs there is evidence of increased susceptibility among the young of injected bucks, and also that when the experimental young, bred under conditions differing slightly from the normal, are compared among themselves the young of severely affected bucks are more susceptible than those of bucks unaffected by the injection and the latter give results closely approximating to the normal. 
Analysis of results also shows that, as might be expected, the effect is of a more or less transient character and that after a certain interval of time has elapsed since the injection of the father the young are of normal resistance. In Table XLV the results are divided according to whether the young were born within or after 12 months from the time of the injection.

\section{TABLE XLV.}

Contrasting the results upon the young of injected bucks born within 12 months of the injection of the parent with those born during the next year.

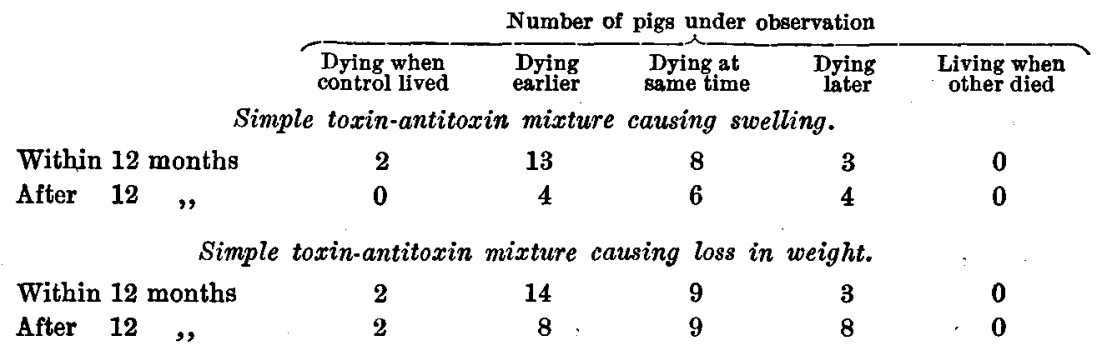

Simple toxin-antitoxin mixture with less than $20 \%$ excess of antitoxin.

\begin{tabular}{|c|c|c|c|c|c|c|c|}
\hline Withi & 12 & nonths & 2 & 9 & 4 & 0 & 0 \\
\hline After & 12 & ," & 1 & 4 & 6 & 4 & 0 \\
\hline & & & $e$ & & rse & & \\
\hline Withi & 12 & nonths & 2 & 2 & $\mathbf{1}$ & 0 & 0 \\
\hline After & 12 & ," & 0 & $\mathbf{3}$ & 4 & 0 & 0 \\
\hline
\end{tabular}

The other groups were only tested within 12 months of the injection of the parent, but among the bucks injected with horse serum alone some were put to breed with normal does at once and the results of the young born within three months of the injection of the parent gave

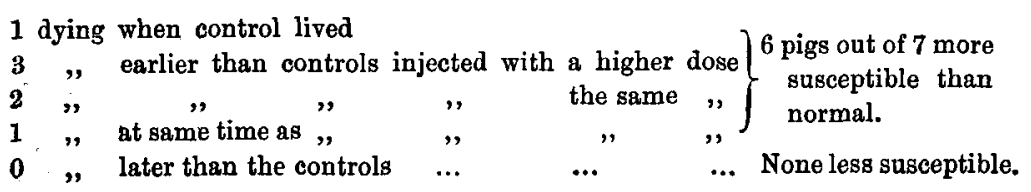

There is strong evidence here that the young of bucks injected with horse serum possess less than normal resistance to diphtheria toxin. A few experiments on guinea-pigs to which alcohol had been administered appeared to show that this also has some effect in lowering the resistance of the offspring to diphtheria toxin. It is thus probable that the results dealt with in this section of the paper are of a non-specific character. 
The condition of increased susceptibility in the offspring is, therefore, obvionsly to be referred to some effect on the male reproductive cell, whether by direct action of the toxin, etc. upon the germ cell, or indirectly by a lowering of the vitality of the animal producing it.

\section{H. Effect of injections upon the rate of breeding of guinea-pigs and the vitality of their young.}

In this section we have accumulated results which show the effect of the injection of the parents upon their rate of breeding and also upon the vitality of their young. In Part 1, Table XVII, we recorded an instance in Cages $100 a$ and $100 b$, two other illustrations are now given as follows:

1. Toxin and antitoxin mixtures with different proportions of antitoxin were injected at the same time into three pregnant does.

1 Test dose of toxin $+1 \cdot 1$ units of antitoxin-Still-births.

$1 \quad " \quad+1 \cdot 3 \quad " \quad, \quad$-Young born alive but died within a few

(ays of birth.

1 " $"$ " $1.5 \quad$ - Young survived.

2. Alcohol was injected into breeding bucks on three or four successive days. A few c.c. were injected, the animals exhibiting severe symptoms of intoxication on each occasion. Four bucks were placed with normal does immediately after the last injection. If both animals in each pair had been normal we would have expected births in all cases within three months, in these cases births occurred at the end of three months in only one case, seven months, and nine months in two others, while the fourth buck was discarded after nine months and the doe was still not pregnant.

So many factors influence the rate of breeding of guinea-pigs that it is necessary when recording results in tabular form to compare only those animals that have been kept under identical conditions.

In the following tables only those pigs are recorded that were kept under the same conditions in the same section of the animal house. In all' cases the parents were injec̈ted when 250 grams in weight and were placed in the breeding runs before they reached 400 grams. Under these conditions a large majority of normal uninjected pigs commence to breed in five months after they have reached 200 grams in weight. The second litter follows usually three months after the first. Tables XLVI and XLVII give the average number of months elapsing between the injection of the parent and the birth of the first and second litters 
respectively for injected does paired with normal bucks. The results are divided according to the nature of the injection and the change of weight ressulting. The separation of the toxin-antitoxin injection into two groups according to whether excess of horse serum was present in the mixture seemed advisable in consideration of the results in Part 2, where it was found that cases of lowered resistance were frequent when a large volume of horse serum was contained in the neutral mixture. The figures appearing under "Toxin into immune young," refer to passively immune does injected with toxin and subsequently used for breeding second generation pigs such as are recorded in Tables XXXIII, XXXIV, and XXXV of Part 2.

\section{TABLE XLVI.}

Showing the average time elapsing between injection of mother and birth of first litter of young divided according to change in weight produced by the injection.

\begin{tabular}{|c|c|c|c|c|}
\hline \multirow[b]{2}{*}{ Nature of injection } & \multicolumn{2}{|c|}{$\begin{array}{l}\text { Months elapsing between injection } \\
\text { and birth of flrst litter }\end{array}$} & \multicolumn{2}{|c|}{$\begin{array}{l}\text { Number of does under } \\
\text { observation }\end{array}$} \\
\hline & Increase in weight & Decrease in weight & Increase in weight & Decrease in weight \\
\hline Toxin and antitoxin & $7 \cdot 6$ & $7 \cdot 9$ & 16 & 11 \\
\hline $\begin{array}{l}\text { Toxin and antitoxin } \\
\text { (excess of serum) }\end{array}$ & $6 \cdot 2$ & $7 \cdot 7$ & 12 & 10 \\
\hline Toxin into immune young & $6 \cdot 9$ & $9 \cdot 2$ & 4 & 11 \\
\hline
\end{tabular}

\section{TABLE XLVII.}

Showing the average time elapsing between injection of mother and birth of second litter of young divided according to change in weight produced by the injection.

\begin{tabular}{|c|c|c|c|c|}
\hline & \multicolumn{2}{|c|}{$\begin{array}{l}\text { Months elapsing between injection } \\
\text { and birth of second litter }\end{array}$} & \multicolumn{2}{|c|}{$\begin{array}{c}\text { Number of does under } \\
\text { observation }\end{array}$} \\
\hline Nature of injection & Increase in weight & Decrease in weight & Increase in weight & Decrease in weight \\
\hline Toxin and antitoxin. & $10 \cdot 6$ & $11 \cdot 6$ & 12 & 8 \\
\hline $\begin{array}{l}\text { Toxin and antitoxin } \\
\text { (excess of serum) }\end{array}$ & $8 \cdot 9$ & $11 \cdot 1$ & 13 & 10 \\
\hline Toxin into immune young & $9 \cdot 0$ & $11 \cdot 5$ & 4 & 6 \\
\hline
\end{tabular}

It will be seen that in all cases breeding was delayed beyond the average time for normal pigs of the same weight (five months for first litter and eight months for second). This was slightly more marked when a decrease in weight resulted from the injection.

It was noticed that a considerable proportion of. still-births accurred among groups of severely affected animals. Table XLVIII was prepared to demonstrate this point. We must emphasize here the 
identity of conditions of breeding of all pigs included in the tables because our experience in breeding normal guinea-pigs for routine purposes shows that the proportion of still-births is greatly increased by adverse conditions.

\section{TABLE XLVIII.}

Showing number of still-births occurring among the various groups of pigs under observation divided according to change of weight occurring after the injection.

\begin{tabular}{|c|c|c|c|c|c|c|c|}
\hline \multirow[b]{3}{*}{$\begin{array}{c}\text { Which } \\
\text { parent } \\
\text { injected }\end{array}$} & \multirow[b]{3}{*}{$\begin{array}{c}\text { Nature of } \\
\text { injection }\end{array}$} & \multicolumn{6}{|c|}{ Change of weight of parent } \\
\hline & & \multicolumn{3}{|c|}{ Increase in weight } & \multicolumn{3}{|c|}{ Decresse in weight } \\
\hline & & $\begin{array}{l}\text { Number } \\
\text { still-births }\end{array}$ & $\begin{array}{l}\text { Total } \\
\text { births }\end{array}$ & $\begin{array}{l}\text { Percentage } \\
\text { number of } \\
\text { still-births }\end{array}$ & $\begin{array}{l}\text { Number } \\
\text { of } \\
\text { still-births }\end{array}$ & $\begin{array}{l}\text { Total } \\
\text { births }\end{array}$ & $\begin{array}{l}\text { Percentare } \\
\text { number of } \\
\text { still-births }\end{array}$ \\
\hline Doe only & Toxin \& antitoxin & 1 & 66 & $1.5 \%$ & 12 & 84 & $14 \cdot 3 \%$ \\
\hline Doe only & $\begin{array}{l}\text { Toxin \& antitoxin } \\
\text { (excess of serum) }\end{array}$ & 8 & 66 & $12 \cdot 1$ & 12 & 78 & $15 \cdot 4$ \\
\hline Doe only & $\begin{array}{l}\text { Toxin into im- } \\
\text { mune doe }\end{array}$ & 0 & 10 & 0 & 18 & 57 & $31 \cdot 6$ \\
\hline Buck only & Toxin \& antitoxin & $\mathbf{3}$ & 13 & $23 \cdot 1$ & 14 & 56 & $25 \cdot 0$ \\
\hline Buck only & $\begin{array}{l}\text { Toxin \& antitoxin } \\
\text { (excess of serum) }\end{array}$ & - & - & - & 8 & 28 & $28 \cdot 6$ \\
\hline \multirow[t]{2}{*}{ Buck \& doe } & Toxin\& antitoxin & 4 & 17 & $23 \cdot 4$ & 4 & 17 & $23 \cdot 4$ \\
\hline & & \multicolumn{3}{|c|}{ Cage $80(L 0)$} & \multicolumn{3}{|c|}{ Cage $79(L+)$} \\
\hline Buck \& doe & Toxin\& antitoxin & 7 & 121 & $5 \cdot 8$ & 19 & 128 & $14 \cdot 8$ \\
\hline
\end{tabular}

Table XLVIII shows that the proportion of still-births is higher among does severely affected by the injection and that the injection of the male parent also affects the number of still-births. Among the bucks the same restrictions occur that no figures are included unless the conditions of breeding were identical.

It will be seen that the presence of excess of horse serum in the toxin-antitoxin mixture increases the number of still-births, and also that the number is high among the young of does passively immune by maternal transmission which have received an injection of toxin. It is somewhat surprising that this table does not show marked irregularities because so many factors contribute to still-births. They are more prevalent among large litters than small and almost invariably occur in five-pig litters: a single litter of this size would greatly affect the results. However, in Cages 79 and 80 we have a good comparison dealing with fairly high figures; among L0 parents there were 7 stillbirths in a total of 121 , while in the $\mathrm{L}+$ group there were 19 in a total of 128 .

It was also noticed that as a general rule the young of severely affected pigs took longer to reach the standard weight than those of 
animals less affected. To tabulate such results it is necessary to bear in mind that pigs increase in weight much more rapidly in summer than in winter, also that the fewer pigs there are in a litter the heavier they are at birth and the more rapidly they come up to weight. Possibly other factors may contribute such as whether the young are the first that the doe has given birth to, but our figures are too small to enable us to detect such differences. Table XLIX gives the average number of days taken by various groups of pigs to reach 250 grams weight during the summer.

\section{TABLE XLIX.}

Showing the rate at which pigs of different sized litters reached the standard weight of 250 grams in summer time divided into various groups according to the nature and effect of the injection into the mother.

\begin{tabular}{|c|c|c|c|c|c|c|c|c|c|}
\hline \multirow[b]{2}{*}{ Nature of injection } & \multirow{2}{*}{$\begin{array}{c}\text { Change } \\
\text { of weight }\end{array}$} & \multicolumn{4}{|c|}{$\begin{array}{c}\text { Average number of days coming } \\
\text { up to weight } \\
\text { Number of pigs.in litter }\end{array}$} & \multicolumn{4}{|c|}{$\begin{array}{l}\text { Number of pigs under } \\
\text { observation } \\
\text { Number of pigs in litter }\end{array}$} \\
\hline & & 1 & 2 & 3 & 4 & 1 & 2 & 3 & 4 \\
\hline Toxin and antitoxin! & Increase & $13 \cdot 0$ & $26 \cdot 3$ & $32 \cdot 9$ & - & 4 & 12 & 17 & 0 \\
\hline 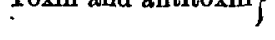 & Decrease & $18 \cdot 0$ & $36 \cdot 7$ & $32 \cdot 4$ & - & 2 & 7 & 27 & 0 \\
\hline Toxin and antitoxin & Increase & $19 \cdot 5$ & $25 \cdot 3$ & $36 \cdot 0$ & $53 \cdot 5$ & 2 & 14 & 18 & 4 \\
\hline with excess of serum $\delta$ & Decrease & $24 \cdot 5$ & $42 \cdot 5$ & $31 \cdot 6$ & $54 \cdot 2$ & 2 & 4 & 15 & 4 \\
\hline Toxin into immune? & Increase & $15 \cdot 5$ & - & $35 \cdot 0$ & 一 & 2 & 0 & 9 & 0 \\
\hline young & Decrease & $21 \cdot 0$ & $25 \cdot 1$ & $36 \cdot 0$ & $54 \cdot 6$ & 4 & 13 & 3 & $\mathbf{3}$ \\
\hline
\end{tabular}

\section{TABLE L.}

Showing the rate at which pigs of different sized litters reached the standard weight of 250 grams in winter time divided into various groups according to the nature and effect of the injection into the mother.

\begin{tabular}{|c|c|c|c|c|c|c|c|c|c|}
\hline \multirow[b]{2}{*}{ Nature of injection } & \multirow{2}{*}{$\begin{array}{c}\text { Change } \\
\text { of weight }\end{array}$} & \multicolumn{4}{|c|}{$\begin{array}{l}\text { Average number of days } \\
\text { coming up to weight } \\
\text { Number of pigs in litter }\end{array}$} & \multicolumn{4}{|c|}{$\begin{array}{l}\text { Number of pigs under } \\
\text { observation } \\
\text { Number of pigs in litter }\end{array}$} \\
\hline & & 1 & 2 & 3 & 4 & 1 & 2 & 3 & 4 \\
\hline toxin & Increase & $26 \cdot 2$ & $45 \cdot 9$ & $59 \cdot 0$ & $\longrightarrow$ & 5 & 12 & 10 & 0 \\
\hline 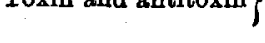 & Decrease & $25 \cdot 5$ & $46 \cdot 2^{\circ}$ & $57 \cdot 3$ & $44 \cdot 5$ & 2 & 4 & 3 & 4 \\
\hline Toxin and antitoxin & Increase & $35 \cdot 3$ & $42 \cdot 2$ & $59 \cdot 0$ & - & 9 & 12 & 7 & 0 \\
\hline with excess of serum & Decrease & $33 \cdot 0$ & $38 \cdot 7$ & $55 \cdot 9$ & - & 1 & 8 & 8 & 0 \\
\hline Toxin into immune & Increase & - & $37 \cdot 5$ & $\longrightarrow$ & - & $\mathbf{0}$ & 6 & $\mathbf{0}$ & 0 \\
\hline young & Decrease & - & $\cdots$ & $45 \cdot 0$ & - & $\mathbf{0}$ & 0 & $\mathbf{3}$ & 0 \\
\hline
\end{tabular}

It would appear from Table XLIX that in cases of litters comprising one and two pigs the effect of the treatment on the mother is marked, in all cases the young of severely affected does took the longest times 
to reach the standard weight. This effect is not noticeable in litters of three or four pigs, nor in the winter time (given in Table L). It is probable that the effect is masked wherever the natural conditions are unfavourable to rapid growth.

\section{SUMmart-Part 3.}

1. A male guinea-pig which has received a single injection of a mixture of diphtheria toxin-antitoxin causing severe constitutional disturbance, may beget offspring of slightly lower resistance than normal to diphtheria toxin.

2. This effect is generally restricted to young born within twelve months after the injection of the father, being rarely noticed in the young of later litters.

3. An increased susceptibility to diphtheria toxin is likewise observed in the offspring of male or female guinea-pigs which have received a large dose of horse serum. The greater susceptibility to diphtheria toxin of the young of male guinea-pigs which have been treated with toxin-antitoxin may therefore be non-specific in character.

4. The injection of diphtheria toxin-antitoxin mixtures into guinea-pigs whether male or female reduces their rate of breeding and lowers the vitality of their young.

5. These effects are most pronounced when the toxin-antitoxin mixture produces severe constitutional disturbance or contains excess of horse serum.

\section{Conclusion.}

In reviewing the results recorded in Parts 1,2 and 3 of this paper, bearing upon some of the problems connected with immunity to diphtheria toxin exhibited in the case of the guinea-pig, we have seen that the maximum immunity response to diphtheria toxin, as indicated by the degree of passive immunity of the young, is obtained when an, injection of a mixture of diphtheria toxin and antitoxin contains between 1 and 1.2 units of antitoxin to the test dose of toxin. Such a mixture causes considerable constitutional disturbances as shown by reaction at seat of injection and falling off in weight. The immunity induced becomes lešs and less as the quantity of antitoxin in excess increases.

When it is borne in mind that in order to produce immunity by the injection of a mixture of toxin and antitoxin a comparatively: large dose 
of toxin is required, it appears extraordinary that a dose of toxin slightly above the minimum fatal dose confers lasting immunity of a similar order when injected into young which are passively immune by maternal transmission; although a dose of toxin injected into a guineapig not possessing this initial passive condition of immunity will not, so far as we know, produce even the slightest degree of immunity. A difference between effecis of injection of toxin-antitoxin mixtures in the guinea-pig and those of injection of toxin alone in the passively immune guinea-pig was evidenced by the relationship between the reaction and the degree of immunity produced, since generally the larger the reaction with toxin-antitoxin mixtures, the greater the immunity, while with toxin alone in passively immune guinea-pigs the reverse holds good.

The two cases are obviously different, in the one the toxin meets the antitoxin already circulating in the body, while in the other the interaction takes place at the site of inoculation. The process of combination is therefore probably more gradual in the one than in the other.

A single injection, or even a succession of injections of toxin alone into a guinea-pig not possessing any initial antitoxin, is unable to confer any immunity. Whatever these differences may signify it is clear that in order to give the first stimulus to the production of antitoxin in the body cells of the guinea-pig, it is necessary that some antitoxin be present either in the fluids of the body or introduced at the time with toxin. This is in line with results obtained in connection with the immunisation of horses which we hope shortly to publish.

A matter of considerable interest is the great length of time following the injection of an immunity producing mixture of toxinantitoxin or of toxin alone in a passively immune pig during which the doe can confer passive immunity upon her young. This may be taken as evidence of circulating antitoxin for several years after the injection and yet the young of such pigs when over two months old rarely possess even a trace of immunity. It may be inferred that the circulating antitoxin in the young is all destroyed or excreted within two months from birth, while the mother that has received the single injection of a toxin-antitoxin mixture continues to produce antitoxin for a considerable time. It is evident that the machinery of side-chain production, having once started, continues in the direction of over production for at least two years after the stimulus has been given.

An injurious influence upon the germ cells is brought into evidence when the father alone has been injected, while injections given to 
mothers during pregnancy and suckling likewise influence the young in the direction of increased susceptibility, showing that the materials necessary for the nutrition of the young may likewise be deficient in quality or quantity or in both respects, and it is therefore possible that most or all the cells of the body may suffer to some extent as the result of an injection giving rise to production of immunity. As measured by the resistance of offspring to intoxication indicated by tolerance or non-tolerance of a slightly sub-lethal dose this injurious effect of an injection might appear very small, but when taken in conjunction with other effects observed, such as depression of procreative power, exhibited by average delayed appearance of first litters and increase in percentage of still-births, the injury resulting from such an injection may be considerable.

In the case of the injected mother it was shown that although earlier litters possess immunity, later ones may consist of more than normally susceptible young, thus indicating that whatever antitoxin might still be in circulation in the mother is insufficient to confer any immunity on the young, and the injurious influence of the toxin is then brought into evidence.

It does not appear that this lowered resistance to diphtheria toxin is specific, and it has been seen that similar results have been obtained when the parents have been injected with such foreign substances as horse serum, and possibly after repeated massive doses of alcohol.

We have since demonstrated the existence of circulating antitoxin in injected guinea-pigs whose young can tolerate large doses of toxin, while in no case have we found antitoxin in the blood of normal guineapigs. Further work is now being conducted upon this subject, dealing with the amount of antitoxin produced by the injection of toxinantitoxin mixtures in guinea-pigs and the relationship between the circulating antitoxin and the resistance of the animal and its young to toxin.

In view of the possible application of our results to the human subject we are now investigating whether, under cover of antitoxin introduced or normally existent in the blood, a condition of active immunity may be induced by the injection of a small dose of toxin giving rise to little or no constitutional disturbance. We have already found that differences occur in the normal antitoxin value of the blood of different individuals. 